\title{
Involvement of calcium-sensing receptor activation in the alleviation of intestinal inflammation in a piglet model by dietary aromatic amino acid supplementation
}

\author{
Hongnan Liu ${ }^{1,2}$, Bie Tan ${ }^{1 *}$, Bo Huang ${ }^{1,3}$, Jianjun $\mathrm{Li}^{1}$, Jing Wang ${ }^{1,3}$, Peng Liao ${ }^{1}$, Guiping Guan ${ }^{1}$, \\ Peng $\mathrm{Ji}^{4}$ and Yulong Yin $^{1 *}$ \\ ${ }^{1}$ Laboratory of Animal Nutritional Physiology and Metabolic Process, Key Laboratory of Agro-ecological Processes in \\ Subtropical Region, National Engineering Laboratory for Pollution Control and Waste Utilization in Livestock and Poultry \\ Production, Institute of Subtropical Agriculture, Chinese Academy of Sciences, Changsha 410125, Hunan, People's \\ Republic of China \\ ${ }^{2}$ Hunan Co-Innovation Center of Animal Production Safety, CICAPS, Changsha 410128, Hunan, People's Republic of China \\ ${ }^{3}$ College of Advanced Agricultural Sciences, University of Chinese Academy of Sciences, Beijing 100008, People's Republic of \\ China \\ ${ }^{4}$ Department of Nutrition, University of California, Davis, CA 95616, USA
}

(Submitted 31 May 2018 - Final revision received 29 August 2018 - Accepted 3 September 2018)

\section{Abstract}

$\mathrm{Ca}^{2+}$-sensing receptor (CaSR) represents a potential therapeutic target for inflammatory bowel diseases and strongly prefers aromatic amino acid ligands. We investigated the regulatory effects of dietary supplementation with aromatic amino acids - tryptophan, phenylalanine and tyrosine (TPT) - on the CaSR signalling pathway and intestinal inflammatory response. The in vivo study was conducted with weanling piglets using a $2 \times 2$ factorial arrangement in a randomised complete block design. Piglets were fed a basal diet or a basal diet supplemented with TPT and with or without inflammatory challenge. The in vitro study was performed in porcine intestinal epithelial cell line to investigate the effects of TPT on inflammatory response using NPS-2143 to inhibit CaSR. Dietary supplementation of TPT alleviated histopathological injury and decreased myeloperoxidase activity in intestine challenged with lipopolysaccharide. Dietary supplementation of TPT decreased serum concentration of pro-inflammatory cytokines (IL-1 $\beta$, IL-6, IL-8, IL-12, granulocyte-macrophage colony-stimulating factor, TNF- $\alpha$ ), as well as the mRNA abundances of pro-inflammatory cytokines in intestine but enhanced anti-inflammatory cytokines IL- 4 and transforming growth factor- $\beta$ mRNA levels compared with pigs fed control diet and infected by lipopolysaccharide. Supplementation of TPT increased CaSR and phospholipase $\mathrm{C} \beta 2$ protein levels, but decreased inhibitor of NF- $\kappa \mathrm{B}$ kinase $\alpha / \beta$ and inhibitor of NF- $\kappa \mathrm{B}$ (I $\kappa \mathrm{B}$ ) protein levels in the lipopolysaccharide-challenged piglets. When the CaSR signalling pathway was blocked by NPS-2143, supplementation of TPT decreased the CaSR protein level, but enhanced phosphorylated NF- $\kappa \mathrm{B}$ and I $\kappa \mathrm{B}$ levels in IPEC-J2 cells. To conclude, supplementation of aromatic amino acids alleviated intestinal inflammation as mediated through the CaSR signalling pathway.

Key words: Aromatic amino acids: Calcium-sensing receptor: Inflammatory response: Piglet model

Various stressful factors are associated with gastrointestinal disturbance, increased risk of enteric infections and accompanied inflammatory response in human and animals ${ }^{(1)}$. The intestine is the predominant organ for nutrient digestion and absorption and the major site subjected to a high level of external stimulation ${ }^{(2)}$. During immune stimulation, the integrity of the intestinal mucosa may be damaged by the secretion of many inflammatory cytokines such as IL-1, IL-6 and TNF- $\alpha^{(3,4)}$. Certain bacterial endotoxins, such as lipopolysaccharide (LPS), activate the innate immunity and induce inflammatory reactions through the NF- $\kappa \mathrm{B}$ signalling pathway, which induces the secretion of proinflammatory cytokines in enterocytes, compromising the mucosal layer and the intestinal barrier functions in piglets ${ }^{(5,6)}$. In addition, LPS transmits cellular signal after being recognised by

Abbreviations: BW, body weight; CaSR, calcium-sensing receptor; CCL2, CC chemokine ligand 2; GM-CSF, granulocyte-macrophage colony-stimulating factor; IKK, inhibitor of NF- $\kappa \mathrm{B}$ kinase; I $\kappa \mathrm{B}$, inhibitor of NF- $\kappa \mathrm{B}$; LPS, lipopolysaccharide; MCP, monocyte chemoattractant protein; MPO, myeloperoxidase; Phe, phenylalanine; PLC, phospholipase C; p-NF- $\kappa$ B, phosphorylated NF- $\kappa \mathrm{B}$; TGF, transforming growth factor; TPT, tryptophan, phenylalanine and tyrosine; Trp, tryptophan; Tyr, tyrosine.

* Corresponding authors: B. Tan, email bietan@isa.ac.cn; Y. Yin, email yinyulong@isa.ac.cn 
toll-like receptor 4 (TLR4), the activation of which induces the expression of inflammatory cytokines, including IL-6, TNF- $\alpha$ and IL- ${ }^{(7)}$. Therefore, an LPS-challenged animal model and an intestinal epithelial cell model have been widely used to study the anti-inflammatory effect of various nutrients ${ }^{(8)}$.

$\mathrm{NF}-\kappa \mathrm{B}$ is the main molecular target involved in inflammatory response $^{(9)}$. The activation of the NF- $\kappa \mathrm{B}$ signalling pathway can induce an intestinal immune response ${ }^{(10)}$. Owing to the presence of calcifications at sites of chronic inflammation or ischaemic necrosis, the Ca-sensing receptor (CaSR) is one of the key targets for the prevention of chronic inflammation ${ }^{(11)}$. The activation of CaSR can inhibit the activity of NF- $\kappa \mathrm{B}$, subsequently inhibiting the LPS-induced production of proinflammatory cytokines ${ }^{(12)}$.

$\mathrm{L}$-Amino acids are allosteric activators of $\mathrm{CaSR}^{(13)}$. It is known that aromatic L-amino acids have a higher affinity for CaSR than aliphatic and polar L-amino acids ${ }^{(14)}$. Recent studies have shown that L-tryptophan (Trp) can recruit $\beta$-arrestin 2 by activating the CaSR signalling pathway in Caco- 2 and HT-29 cell lines, therefore inhibiting the $\mathrm{NF}-\kappa \mathrm{B}$ signalling pathway, blocking inflammatory signal transduction and subsequently exerting an anti-inflammatory effect ${ }^{(15)}$.

Together, we hypothesise that appropriate ratio aromatic amino acids. In this study, LPS-induced intestinal inflammation piglet model and porcine jejunal epithelial cell line (IPEC-J2) were used to investigate the regulatory effects of dietary supplementation with aromatic amino acids - tryptophan, phenylalanine and tyrosine (TPT) - on the CaSR signalling pathway and intestinal inflammatory response in piglets.

\section{Methods}

\section{Animals and experimental design}

The animal trial was approved by the Institutional Animal Care and Use Committee of the Institute of Subtropical Agriculture, Chinese Academy of Sciences (2013020).

A total of thirty-two cross-bred (Duroc $\times$ Landrace) weanling gilts and barrows with an initial body weight (BW) of 6.66 (SEM $0 \cdot 31) \mathrm{kg}$ were randomly assigned into four treatments (eight piglets/treatment). Each group consisted of an equal number of gilts and barrows. The experimental treatment was designed in a $2 \times 2$ factorial arrangement (diet and LPS challenge) in a complete randomised design. Piglets were fed either a basal diet or the basal diet supplemented with $0.16 \%$ Trp, $0.41 \%$ Phe and $0.22 \%$ Tyr for a period of $21 \mathrm{~d}$. The levels of TPT were determined based on the preliminary experiment, which found that piglets fed diets supplemented with 1.5-fold TPT recommended by the National Research Council ${ }^{(16)}$ showed better performance compared with those fed diets supplemented with 1- or 2-fold TPT based on standardised ileal amino acid digestibility. To balance the $\mathrm{N}$ level with the supplemented TPT diets, alanine ( $1.41 \%$ of diet) was added into the basal diet. The basic dietary composition and nutrient levels are shown in Table 1. All piglets had free access to diets and water.

On day 21 of the experiment, the piglets of each dietary treatment were intraperitoneally injected with either LPS (Escherichia coli strain O5:B55) at a dose of $100 \mu \mathrm{g} / \mathrm{kg}$ BW
Table 1. Composition and nutrient levels of diets (as-fed basis)

\begin{tabular}{lcc}
\hline Ingredients (\%) & Control diet & TPT diet \\
\hline Maize grain & 61.00 & 61.00 \\
Soyabean meal (43\% crude protein) & 9.00 & 9.00 \\
Extruded soyabean & 8.00 & 8.00 \\
Fermented soyabean meal & 5.00 & 5.00 \\
Fish meal & 3.00 & 3.00 \\
Whey powder & 8.00 & 8.00 \\
Soyabean oil & 0.70 & 0.70 \\
Sucrose & 1.00 & 1.00 \\
Calcium dihydrogen phosphate & 0.78 & 0.78 \\
L-Lys HCl (98\%) & 0.64 & 0.64 \\
Limestone powder & 0.50 & 0.50 \\
Antioxidant & 0.10 & 0.10 \\
Salt & 0.30 & 0.30 \\
Premix & 1.00 & 1.00 \\
Zeolite powder & 0.24 & 0.19 \\
Alanine & 0.74 & - \\
L-Trp & - & 0.41 \\
L-Phe & - & 0.22 \\
L-Tyr & - & 0.16 \\
Analysed nutrient content (\%) & & \\
DM & 1.51 & 0.59 .88 \\
Crude protein & 0.23 & 18.45 \\
Lys & 0.89 & 0.40 \\
Trp & 0.55 & 0.31 \\
Phe & & \\
Tyr & 18.41 & \\
\hline
\end{tabular}

TPT, tryptophan, phenylalanine and tyrosine.

* Providing the following amounts of vitamins and minerals per $\mathrm{kg}: \mathrm{Zn}(\mathrm{ZnO}), 50 \mathrm{mg}$; $\mathrm{Cu}\left(\mathrm{CuSO}_{4}\right), 20 \mathrm{mg} ; \mathrm{Mn}(\mathrm{MnO}), 55 \mathrm{mg} ; \mathrm{Fe}\left(\mathrm{FeSO}_{4}\right), 100 \mathrm{mg}$; iodine $(\mathrm{KI}), 1 \mathrm{mg}$; Co $\left(\mathrm{CoSO}_{4}\right), 2 \mathrm{mg}$; $\mathrm{Se}\left(\mathrm{Na}_{2} \mathrm{SeO}_{3}\right), 0.3 \mathrm{mg}$; vitamin $\mathrm{A}, 2.48 \mathrm{mg}$; vitamin $\mathrm{D}_{3}, 0.5 \mathrm{mg}$; vitamin $E, 26.72 \mathrm{mg}$; vitamin $B_{1}, 2 \mathrm{mg}$; vitamin $B_{2}, 4 \mathrm{mg}$; pantothenic acid, $15 \mathrm{mg}$; vitamin $B_{6}, 10 \mathrm{mg}$; vitamin $B_{12}, 0.05 \mathrm{mg}$; nicotinic acid, $30 \mathrm{mg}$; folic acid, $2 \mathrm{mg}$; vitamin $\mathrm{K}_{3}, 1.5 \mathrm{mg}$; biotin, $0.2 \mathrm{mg}$; choline chloride, $800 \mathrm{mg}$ and vitamin $\mathrm{C}, 100 \mathrm{mg}$. The premix did not contain additional $\mathrm{Cu}, \mathrm{Zn}$, antibiotics or probiotics.

or the same volume of $0.9 \%$ sterilised saline, respectively. All piglets were euthanised with $4 \%$ pentobarbital sodium ( $40 \mathrm{mg} / \mathrm{kg} \mathrm{BW}$ ) $4 \mathrm{~h}$ post injection. Blood samples were collected from the jugular vein and allowed to stand at $4^{\circ} \mathrm{C}$ for $4 \mathrm{~h}$. Serum samples were obtained by centrifugation at $2000 \mathrm{~g}$ for $15 \mathrm{~min}$ and stored at $-80^{\circ} \mathrm{C}$ until further analysis. All piglets were dissected to collect mid-jejunum, mid-ileum, anterior colon and posterior colon segments. All tissue samples were snap-frozen in liquid $\mathrm{N}_{2}$ and stored at $-80^{\circ} \mathrm{C}$. Extra-intestinal samples $(2 \mathrm{~cm})$ of each segment were rinsed with pre-cooling saline and fixed in formaldehyde solution.

\section{Analysis of serum concentrations of cytokines}

Serum concentrations of IL- $1 \beta$, IL-4, IL-6, IL-8, IL-12, granulocyte-macrophage colony-stimulating factor (GM-CSF), transforming growth factor (TGF)- $\beta 1$ and TNF- $\alpha$ were determined by multiplex ELISA system according to the manufacturer's protocol $^{(17)}$. The signals were visualised using InnoScan 300 Microarray Scanner (Innopsys) at $532 \mathrm{~nm}$ and the quantitative data analysis was performed using the Quantibody ${ }^{\circledR} \mathrm{Q}$-Analyzer (QAP-CYT-1; RayBiotech Inc.).

\section{Histopathological grading}

Histopathological grading of jejunum, ileum, anterior colon and posterior colon samples was performed as described 
previously ${ }^{(18)}$. Briefly, jejunal and ileal tissues were fixed in $10 \%$ buffered formalin solution and embedded in paraffin after a macroscopic evaluation. The embedded specimens were then sectioned $(6 \mu \mathrm{m})$, stained with haematoxylineosin and examined by light microscopy. Histological scoring was carried out by a veterinary and blinded pathologist using the methods that ranged from 0 (minimal injury) to 15 (maximal injury) corresponding to four grades that included mononuclear or polymorph nuclear cell infiltration, histological injury and erosion or epithelial hyperplasia $^{(18)}$.

\section{Analysis of myeloperoxidase activity in the colon}

Colon samples were homogenised in ten volumes of ice-cold potassium phosphate buffer ( $\mathrm{pH}$ 6.0) containing $0.5 \%$ hexadecyl-trimethyl ammonium hydroxide through highpressure homogeniser at $4^{\circ} \mathrm{C}$. The homogenate was centrifuged at $700 \mathrm{~g}$ at $4^{\circ} \mathrm{C}$ for $15 \mathrm{~min}$ and the supernatant was diluted to a total of $50 \mu \mathrm{l}$ each in PBS ( $\mathrm{pH}$ 6.0) containing

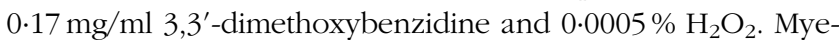
loperoxidase (MPO) activity was assessed by measuring $\mathrm{H}_{2} \mathrm{O}_{2}-$ dependent oxidation of 3,3'-imethoxybenzidine. One unit of enzyme activity is defined as the amount of MPO present that causes a change in absorbance per min at $460 \mathrm{~nm}$ and $37^{\circ} \mathrm{C}^{(19,20)}$.

\section{Real-time $P C R$}

Total RNA was isolated from the jejunum, ileum, anterior colon and posterior colon samples using a Trizol Reagent (Invitrogen) according to the manufacturer's instructions. The extracted RNA was dissolved in diethylpyrocarbonate (DEPC)-treated water, and its concentration was assessed using an Eppendorf Biophotometer (Eppendorf AG) and its integrity verified by electrophoresis on a $1 \%$ agarose gel. After DNase I treatment (Takara), $1 \mu \mathrm{g}$ of total RNA was used as a template for complementary DNA (cDNA) synthesis using an oligo(dT) primer (Takara). The resultant cDNA was diluted and used for evaluating gene expression.

All primers were developed previously for amplification of mRNA sequences of pig (Sus scrofa) (Table 2). Quantitative realtime PCR (qPCR) were performed to analyse the mRNA levels for the target genes including $I L-1 \alpha, I L-1 \beta, I L-8, T N F-\alpha, I L-2, I L-4$, $I L-6, I L-12, T G F-\beta 1, G M-C S F$, interferon- $\gamma(I F N-\gamma), I L-10$ and monocyte chemoattractant protein $(M C P)-1 /$ chemoattractant CC chemokine ligand 2 (CCL2) and a housekeeping gene, $\beta$-actin. A $10-\mu \mathrm{l}$ reaction system was applied, which includes $0.5 \mu \mathrm{l}$ of each forward and reverse primer, $2 \mu \mathrm{l}$ of cDNA, $2 \mu \mathrm{l}$ of DEPC-treated water and $5 \mu \mathrm{l}$ of SYBR Premix Ex Taq (Takara Bio Inc.). The qPCR was carried out (Lightcycler-480I I; Roche Diagnostics $\mathrm{GmbH})$ as previously described ${ }^{(21)}$. The relative mRNA levels of target genes were expressed as $2^{-\Delta \Delta C_{\mathrm{t}}}$, where $\Delta \Delta C_{\mathrm{t}}=\left(C_{\mathrm{t}}\right.$ Target $\left.-C_{\mathrm{t} \beta \text {-actin }}\right)_{\text {treatment }}-\left(C_{\mathrm{t} \text { Target }}-C_{\mathrm{t} \beta \text {-actin }}\right)_{\text {control. }}$. Data are expressed as the relative values to those in basal-diet-treated piglets injected with saline.
Table 2. Primers used for real-time PCR

\begin{tabular}{|c|c|c|}
\hline Gene & Accession no. & Primers $\left(5^{\prime}-3^{\prime}\right)$ \\
\hline$\beta$-Actin & XM_0031242803 & $\begin{array}{l}\text { F: CTGCGGCATCCACGAAACT } \\
\text { R: AGGGCCGTGATCTCCTTCTG }\end{array}$ \\
\hline IL-6 & NM_214403.1 & $\begin{array}{l}\text { F: TCCAGCATCATTGCATCATC } \\
\text { R: GGCTCCACTCACTCCACAAG }\end{array}$ \\
\hline$I L-12$ & NM_214097.2 & $\begin{array}{l}\text { F: ATCTCGGTTGGTGTTGTTCC } \\
\text { R: GGGTATCTCGTCCTCTGTCC }\end{array}$ \\
\hline$I L-4$ & NM_214340.1 & $\begin{array}{l}\text { F: CCCGAGTGTCAAGTGGCTTA } \\
\text { R: TGATGATGCCGAAATAGCAG }\end{array}$ \\
\hline $\begin{array}{l}\text { GM- } \\
\qquad C S F\end{array}$ & NM_2141182 & $\begin{array}{l}\text { F: CGGCTGTGATGAATGAAACC } \\
\text { R: GTGCTGCTCATAGTGCTTGG }\end{array}$ \\
\hline$I F N-\gamma$ & NM_2139481 & $\begin{array}{l}\text { F: TTCAGCTTTGCGTGACTTTG } \\
\text { R: GGTCCACCATTAGGTACATCTG }\end{array}$ \\
\hline$T N F-a$ & NM_214022.1 & $\begin{array}{l}\text { F: ACAGGCCAGCTCCCTCTTAT } \\
\text { R: CCTCGCCCTCCTGAATAAAT }\end{array}$ \\
\hline IL-10 & NM_214041.1 & $\begin{array}{l}\text { F: GGGCTATTTGTCCTGACTGC } \\
\text { R: GGGCTCCCTAGTTTCTCTTCC }\end{array}$ \\
\hline$M C P-1$ & NM_2142141 & $\begin{array}{l}\text { F: CCTCATCCTCCAGCATGAAGGTCTC } \\
\text { TGC } \\
\text { R: GGTGGAGTCAGGCTTCAAGGCTTCGG }\end{array}$ \\
\hline$I L-1 \beta$ & NM_214055.1 & $\begin{array}{l}\text { F: GCTAACTACGGTGACAACAA } \\
\text { R: TCTTCATCGGCTTCTCCACT }\end{array}$ \\
\hline$I L-2$ & NM_213861.1 & $\begin{array}{l}\text { F: TGCACTAACCCTTGCACTCA } \\
\text { R: CAACTGTAAATCCAGCAGCAA }\end{array}$ \\
\hline IL-8 & NM_213867.1 & $\begin{array}{l}\text { F: TGAGAAGCAACAACAACAGCA } \\
\text { R: CAGCACAGGAATGAGGCATA }\end{array}$ \\
\hline$I L-18$ & NM_213997.1 & $\begin{array}{l}\text { F: ACGATGAAGACCTGGAATCG } \\
\text { R: GGCTTGATGTCCCTGGTTAAT }\end{array}$ \\
\hline IL-1a & NM_214029.1 & $\begin{array}{l}\text { F: ACCCGACTGTTTGTGAGTGC } \\
\text { R: TTCCCAGAAGAAGAGGAGACTG }\end{array}$ \\
\hline$T G F-\beta 1$ & NM_214015.1 & $\begin{array}{l}\text { F: AAGCGGCAACCAAATCTATG } \\
\text { R: CCCGAGAGAGCAATACAGGT }\end{array}$ \\
\hline
\end{tabular}

F, forward; R, reverse; GM-CSF, granulocyte-macrophage colony-stimulating factor; IFN- $\gamma$, interferon- $\gamma ;$ MCP-1, monocyte chemoattractant protein-1; TGF- $\beta 1$, transforming growth factor $-\beta 1$.

\section{Western blotting}

Jejunum, ileum and anterior colon samples were collected and the protein levels of $\beta$-actin, CaSR, phospholipase C (PLC) $\beta 2$, $\mathrm{NF}-\kappa \mathrm{B}$ p 65 , phosphorylated NF- $\kappa \mathrm{B}(\mathrm{p}-\mathrm{NF}-\kappa \mathrm{B}) \mathrm{p} 65$, inhibitor of $\mathrm{NF}-\kappa \mathrm{B}$ kinase (IKK) $\alpha / \beta$, inhibitor of NF- $\kappa \mathrm{B}$ (I $\kappa \mathrm{B})$ were determined as described previously ${ }^{(22)}$. The following antibodies were used for protein quantification: $\beta$-actin (1:1000; Cell Signaling Technology), CaSR (1:1000; Bioss Inc.), PLC $\beta 2$ (1:1000; Antibodies-Online), NF- $\kappa$ B p65 (1:1000; Cell Signaling Technology), p-NF- $\kappa$ B p65 (Ser536) (1:1000; Cell Signaling Technology), IKK $\alpha / \beta$ (1:400; Santa Cruz Biotechnology) and I $\kappa$ B (1:1000; Cell Signaling Technology). Data are expressed relative to the values of piglets fed the basal diet without LPS challenge.

\section{Cell culture and treatment}

A porcine jejunal epithelial cell line, IPEC-J2, was seeded in $10-\mathrm{mm}$ cell culture dishes and cultured with high-glucose (25 mm) Dulbecco's modified Eagle's medium (Hyclone) containing $10 \%$ fetal bovine serum (Gibico) and $1 \%$ antibiotic solution (P/S; Sigma) at $37^{\circ} \mathrm{C}$ in a $5 \% \mathrm{CO}_{2}$ incubator. After an overnight incubation, cells were incubated in medium containing the following: (1) normal TPT (0.08 mM Trp $+0.4 \mathrm{~mm}$ 
Phe $+0.4 \mathrm{~mm}$ Tyr), (2) normal TPT with CaSR agonist (R568, $0.05 \mu \mathrm{M}$ ), (3) normal TPT with CaSR inhibitor (NPS-2143, $0.08 \mu \mathrm{M})$, (4) supplemented TPT $(0.16 \mathrm{~mm}$ Trp $+0.8 \mathrm{~mm}$ Phe + $0.8 \mathrm{~mm}$ Tyr $)$ and (5) supplemented TPT (0.16 mm Trp +0.8 mm Phe $+0.8 \mathrm{~mm}$ Tyr) with CaSR inhibitor (NPS-2143, 0.08 $\mu \mathrm{M}$ ), respectively. After $20 \mathrm{~h}$ of incubation, $100 \mu \mathrm{g} / \mathrm{ml}$ of LPS (E. coli strain O5:B55) was added to induce inflammation for $4 \mathrm{~h}$. The medium was removed and cells were washed with cold PBS and collected using Trizol reagent or lysis buffer for the analysis of relative cytokines mRNA and CaSR pathway protein level, as described in the animal experiment.

\section{Statistical analysis}

All data analysis was performed by ANOVA using the general linear model procedures of SPSS (SPSS Inc.). The statistical model included the effects of challenge (saline or LPS), diet (basal or TPT) and their interactions for the in vivo study. In the in vitro study, the statistical model included treatment as a fixed effect. The differences among treatments were evaluated using Tukey's test. Data are presented as means with their standard errors. $P$ values $<0.05$ were taken to indicate significance.

\section{Results}

\section{Growth performance}

There were no differences $(P>0.05)$ in initial BW, final BW, average daily gain and daily feed intake between control and TPT treatments. The feed:gain ratio was decreased $(P<0.05)$ by TPT supplementation (Table 3).

\section{Colonic myeloperoxidase activity}

MPO activity was shown in Table 4. LPS injection increased MPO activity in the anterior colon when piglets were fed the control diet, whereas an opposite direction was observed in piglets fed the TPT diet (diet $\times$ LPS,$P<0.05$ ). In the posterior colon, a significant suppression on MPO activity was observed by diet rather (diet, $P<0.05$ ) than LPS $(P>0.05)$.

\section{Histopathological grading of the intestine}

Intraperitoneal injection of LPS induced the higher score of histopathological grading in the jejunum, ileum and posterior colon (LPS, $P<0.05$ ). Dietary supplementation with TPT decreased (diet $\times$ LPS, $P<0.05$ ) the score of histopathological grading of ileum, anterior colon and posterior colon in LPStreated piglets but not $(P>0.05)$ in saline-injected piglets (Table 5).

\section{Serum cytokine concentrations}

Intraperitoneal injection of LPS increased the serum concentrations of IL- $1 \beta$, IL- 6 , IL-8, IL-12 and TNF- $\alpha$, and decreased serum IL- 4 and TGF- $\beta$ contents in piglets fed the control diet. However, the effects induced by injection of LPS were reversed by dietary supplementation with TPT, which reduced the serum concentrations of IL- $1 \beta$, IL- 6 , IL-8, IL-12 and TNF- $\alpha$ and increased serum IL- 4 and TGF- $\beta$ contents (diet $\times$ LPS, $P<0 \cdot 05$ ) (Fig. 1 ).

\section{Relative cytokine mRNA levels in the intestine}

The relative cytokine mRNA levels in the jejunum are shown in the online Supplementary Table SA. LPS injection induced a significant increase in the mRNA levels of IL- 8 and MCP-1/CCL2 in piglets fed both the control diet and TPT diet (LPS, $P<0.05$ ), as well as IL-6 level in pigs fed the control diet, suggesting the successful induction of enteric inflammation. TPT supplementation alleviated the inflammation as demonstrated by the moderate increase in the mRNA levels of IL-6, IL-8, IL-12, MCP-1/CCL2 and TNF- $\alpha$ in LPS-challenged piglets (diet $\times$ LPS, $P<0.05$ ). However, TPT did not affect mRNA level of cytokines in piglets fed the control diet.

In the ileum, significantly higher mRNA levels of IL- $1 \alpha$ and MCP-1/CCL2 were observed in piglets infected with LPS compared with the pigs fed the control diet (LPS, $P<0.05$ ). TPT treatment reduced mRNA levels of IL-6, IL-12 and TNF- $\alpha$ in LPSchallenged piglets (diet, $P<0 \cdot 05$ ). A significant interaction between diet and LPS was observed on the mRNA level of IL- $1 \beta$, IL-8, IL-12, IL-18, GM-CSF, MCP-1/CCL2 and TNF- $\alpha$ (diet $\times$ LPS, $P<0.05$ ) (online Supplementary Table SB).

In the anterior colon, LPS induced a significant increase in the mRNA levels of IL- $1 \beta$ and MCP-1/CCL2 in piglets fed the control diet (LPS, $P<0 \cdot 05)$. Compared with the LPS-challenged treatment fed with the control diet, dietary supplementation with

Table 3. Effects of dietary supplementation with tryptophan, phenylalanine and tyrosine (TPT) on growth performance of piglets

(Mean values with their standard errors, $n 16$ per treatment)

\begin{tabular}{lrrrrrr}
\hline & \multicolumn{2}{c}{ Control } & & \multicolumn{2}{c}{ TPT } & $P$ \\
\cline { 2 - 3 } \cline { 5 - 6 } & Mean & & SEM & & Mean & SEM \\
\hline Initial body weight $(\mathrm{kg})$ & 6.67 & 0.31 & 6.65 & 0.32 & 0.953 \\
Final body weight $(\mathrm{kg})$ & 10.34 & 0.39 & 10.53 & 0.42 & 0.739 \\
Average daily gain $(\mathrm{g} / \mathrm{d})$ & 174.40 & 8.80 & 184.80 & 9.90 & 0.437 \\
Daily feed intake $(\mathrm{g} / \mathrm{d})$ & 421.10 & 11.20 & & 416.80 & 16.80 & 0.832 \\
Feed:gain ratio & 2.49 & 0.06 & 2.30 & 0.06 & 0.022 \\
\hline
\end{tabular}

Control, basal diet; TPT, basal diet supplemented with $0.16 \%$ tryptophan $+0.41 \%$ phenylalanine $+0.22 \%$ tyrosine . 
Table 4. Effects of dietary supplementation with tryptophan, phenylalanine and tyrosine (TPT) on myeloperoxidase activity in the colon of piglets (Mean values with their standard errors, $n 8$ per treatment)

\begin{tabular}{|c|c|c|c|c|c|c|c|c|c|c|c|}
\hline \multirow[b]{3}{*}{ Items } & \multicolumn{4}{|c|}{ Control diet } & \multicolumn{4}{|c|}{ TPT diet } & & & \\
\hline & \multicolumn{2}{|c|}{ Saline } & \multicolumn{2}{|c|}{ LPS } & \multicolumn{2}{|c|}{ Saline } & \multicolumn{2}{|c|}{ LPS } & \multicolumn{3}{|c|}{$P$} \\
\hline & Mean & SEM & Mean & SEM & Mean & SEM & Mean & SEM & Diet & LPS & Diet $\times$ LPS \\
\hline Anterior colon (U/g) & $9 \cdot 83^{a, b}$ & 0.4 & $10 \cdot 58^{a}$ & 0.19 & $10 \cdot 69^{a}$ & 0.2 & $9.55^{\mathrm{b}}$ & 0.09 & 0.711 & 0.409 & 0.001 \\
\hline Posterior colon $(\mathrm{U} / \mathrm{g})$ & $10 \cdot 41^{a}$ & 0.24 & $11 \cdot 31^{\mathrm{a}}$ & 0.73 & $8 \cdot 67^{b}$ & 0.61 & $9 \cdot 15^{\mathrm{b}}$ & 0.53 & 0.004 & $0 \cdot 261$ & $0 \cdot 724$ \\
\hline
\end{tabular}

Control, basal diet; TPT, basal diet supplemented with $0.16 \%$ tryptophan $+0.41 \%$ phenylalanine $+0.22 \%$ tyrosine; LPS, lipopolysaccharide

a,b Mean values within a row with unlike superscript letters were significantly different $(P<0.05)$.

Table 5. Effects of dietary supplementation with tryptophan, phenylalanine and tyrosine (TPT) on histopathological grading of the intestine in piglets (Mean values with their standard errors, $n 8$ per treatment)

\begin{tabular}{|c|c|c|c|c|c|c|c|c|c|c|c|}
\hline \multirow[b]{3}{*}{ Items } & \multicolumn{4}{|c|}{ Control diet } & \multicolumn{4}{|c|}{ TPT diet } & & & \\
\hline & \multicolumn{2}{|c|}{ Saline } & \multicolumn{2}{|c|}{ LPS } & \multicolumn{2}{|c|}{ Saline } & \multicolumn{2}{|c|}{ LPS } & \multicolumn{3}{|c|}{$P$} \\
\hline & Mean & SEM & Mean & SEM & Mean & SEM & Mean & SEM & Diet & LPS & Diet $\times$ LPS \\
\hline Jejeum & $3.25^{b}$ & 0.16 & $7 \cdot 86^{a}$ & 1.26 & $3.86^{\mathrm{b}}$ & 0.4 & $5 \cdot 71^{\mathrm{a}}$ & 0.94 & 0.340 & $<0.001$ & 0.094 \\
\hline Ileum & $4 \cdot 25^{\mathrm{b}}$ & 0.53 & $8.57^{\mathrm{a}}$ & 1.13 & $4.57^{\mathrm{b}}$ & 0.57 & $4 \cdot 14^{\mathrm{b}}$ & 0.74 & 0.013 & 0.018 & 0.005 \\
\hline Anterior colon & $5 \cdot 29^{b}$ & 0.78 & $8.00^{\mathrm{a}}$ & 0.85 & $4 \cdot 38^{\mathrm{b}}$ & 0.63 & $3.86^{\mathrm{b}}$ & 0.4 & 0.001 & 0.120 & 0.026 \\
\hline Posterior colon & $4 \cdot 25^{\mathrm{b}}$ & 0.37 & $9.57^{a}$ & 1.09 & $5 \cdot 00^{b}$ & 0.73 & $4.67^{b}$ & 0.76 & 0.012 & 0.003 & 0.001 \\
\hline
\end{tabular}

Control, basal diet; TPT, basal diet supplemented with $0.16 \%$ tryptophan $+0.41 \%$ phenylalanine $+0.22 \%$ tyrosine; LPS, lipopolysaccharide .

a,b Mean values within a row with unlike superscript letters were significantly different $(P<0.05)$.

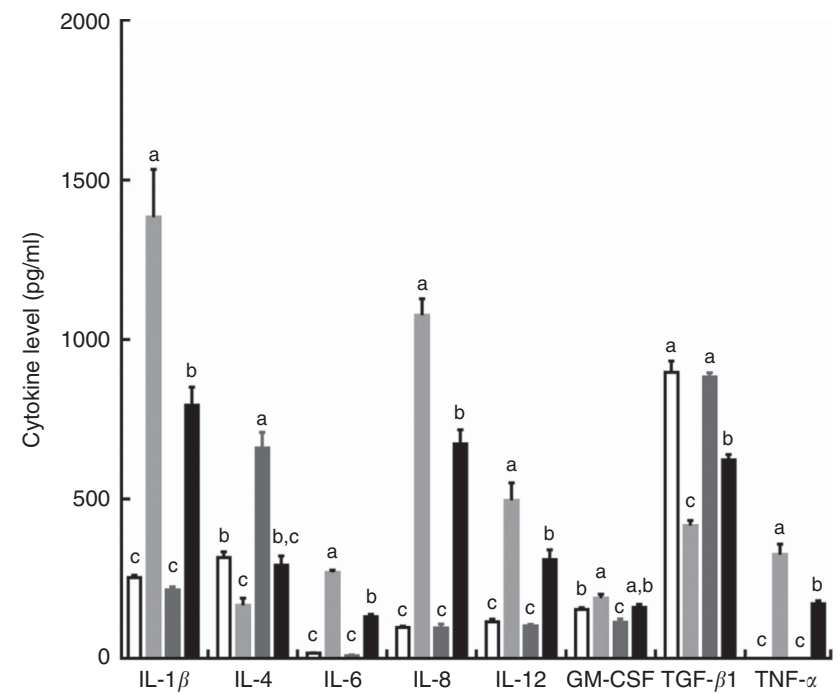

Fig. 1. Dietary supplementation with tryptophan, phenylalanine and tyrosine (TPT) affects serum concentrations of cytokines in piglets. Control, basal diet; TPT, basal diet supplemented with $0.16 \%$ tryptophan $+0.41 \%$ phenylalanine $+0.22 \%$ tyrosine; LPS, lipopolysaccharide; GM-CSF, granulocyte-macrophage colony-stimulating factor; TGF- $\beta$, transforming growth factor- $\beta$. Values are means ( $n 8$ independent experiments), with their standard errors represented by vertical bars. ${ }^{a, b, c}$ Mean values with unlike letters were significantly different $(P<0.05)$. $\square$, Control diet + saline; $\square$, control diet + LPS; $\square$, TPT diet + saline;, TPT diet + LPS.

TPT reduced mRNA level of IL- $1 \alpha$, IL-2, IL- 8 and IL-18 in piglets infected with LPS (diet, $P<0 \cdot 05$ ). In addition, TPT supplementation decreased the mRNA level of IFN- $\gamma$ in shamchallenged piglets (diet, $P<0.05$ ) (online Supplementary Table SC).
In the posterior colon, LPS injection increased the IFN- $\gamma$ mRNA level in piglets fed the control diet (LPS, $P<0.05$ ), whereas TPT supplementation decreased $I L-6, I L-12, I L-18$ and TNF- $\alpha$ mRNA levels in LPS-challenged piglets (diet, $P<0.05$ ). In addition, dietary TPT supplementation decreased the mRNA levels of IL- $1 \beta$, IL-12, IL-18 and TNF- $\alpha$ in the control group (diet, $P<0.05$ ) (online Supplementary Table SD).

\section{Protein expression levels of calcium-sensing receptor and $N F-\kappa B$ signalling pathway in the intestine}

The CaSR and the NF- $\kappa \mathrm{B}$ signalling pathway in the jejunum, ileum and colon were determined by Western blotting, as shown in Fig. 2 and Table 6. In the jejunum, supplementation of TPT significantly increased the protein level of CaSR and PLC $\beta 2$ (diet, $P<0.05$ ). LPS injection increased NF- $\kappa \mathrm{B}$ protein level in the piglets fed the control diet, whereas TPT supplementation significantly reduced the protein levels of IKK $\alpha / \beta$, I $\kappa \mathrm{B}$ and NF$\kappa \mathrm{B}$ (diet $\times$ LPS,$P<0 \cdot 05)$. $\mathrm{p}-\mathrm{NF}-\kappa \mathrm{B}$ was also reduced by TPT supplementation in LPS-challenged piglets $(P<0.05)$.

In the ileum, injection of LPS significantly increased the protein level of $\mathrm{CaSR}$ and $\mathrm{I} \kappa \mathrm{B}$ in the weaned piglets fed the control diet (LPS, $P<0.05$ ). Dietary supplementation of TPT significantly increased CaSR and PLC $\beta 2$, and down-regulated phosphorylation of $\mathrm{NF}-\kappa \mathrm{B}$ and $\mathrm{I} \kappa \mathrm{B}$ protein levels in piglets challenged with LPS (diet, $P<0.05$ ). We observed a significant diet and LPS interaction at the protein levels of $\mathrm{I} \kappa \mathrm{B}$ and phosphorylation of NF- $\kappa \mathrm{B}$ (diet $\times$ LPS, $P<0.05)$.

In the anterior colon, LPS injection increased the protein levels of CaSR, PLC $\beta 2$, IKK $\alpha / \beta$ and I $\kappa \mathrm{B}$ compared with the control group, but the opposite effect was observed in piglets 

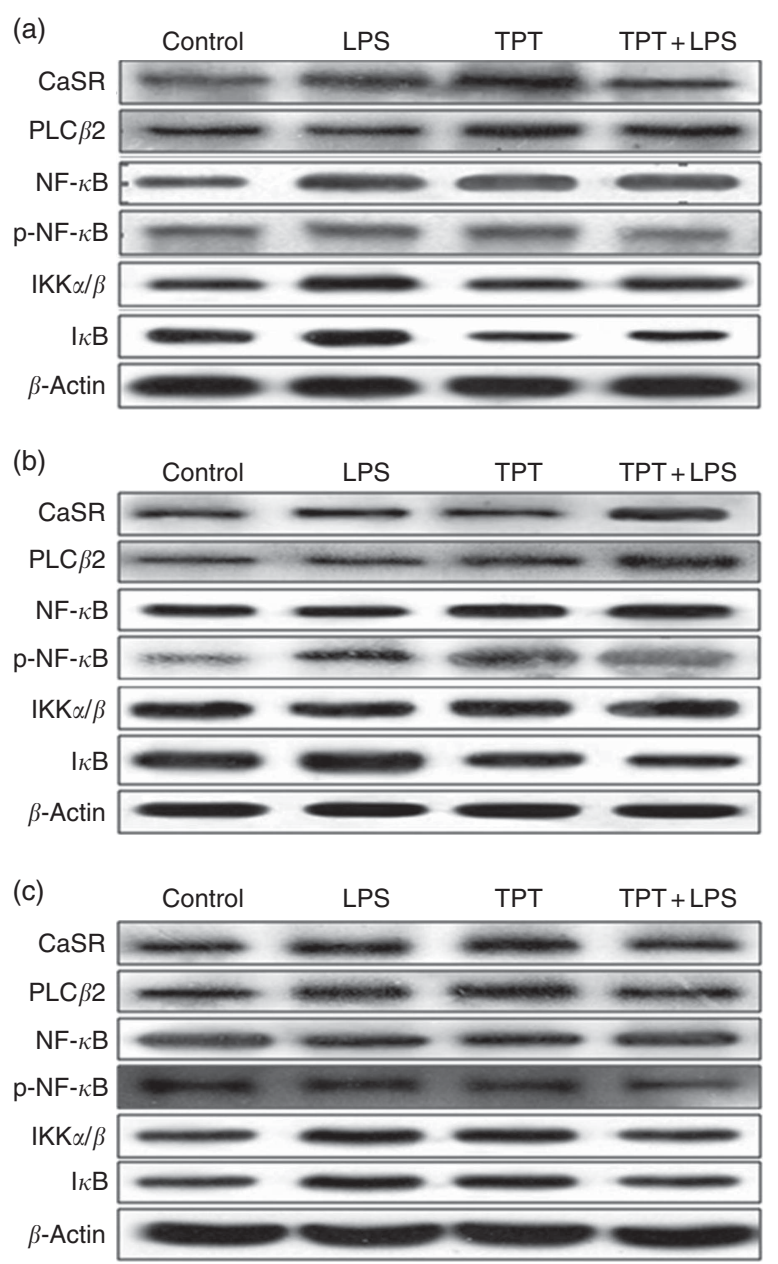

Fig. 2. Representive Western blot images of the calcium-sensing receptor (CaSR) pathway and the NF-kB pathway in the jejunum (a), ileum (b) and anterior colon (c). LPS, lipopolysaccharide; TPT, tryptophan, phenylalanine and tyrosine; PLC, phospholipase C; p-NF-kB, phosphorylated NF-kB; IKK, inhibitor of NF-kB kinase; IkB, inhibitor of NF-kB.

fed the TPT diet (diet $\times$ LPS, $P<0 \cdot 05$ ). $\mathrm{p}-\mathrm{NF}-\kappa \mathrm{B}$ decreased in TPT-supplemented LPS-treated piglets compared with TPTsupplemented saline-treated piglets but not compared with LPStreated piglets fed the control diet (diet, $P<0.05$ ).

\section{Relative cytokine mRNA and calcium-sensing receptor pathway protein level in the cells}

In comparison with the control group, R568 and TPT treatments decreased the mRNA levels of $I L-6$ in IPCE-J2 cells treated with LPS $(P<0.05)$, whereas NPS-2143 significantly increased the mRNA levels of TNFA, IL- $1 \alpha, I L-8, I L-18$ and $G M-C S F(P<0 \cdot 05)$. R568 treatment also reduced the mRNA levels of GM-CSF $(P<0 \cdot 05)$. Adding NPS-2143 in TPT-treated cells significantly increased the mRNA level of $T N F-\alpha$ and $I L-6 \quad(P<0.05)$ (Table 7).

The protein levels of CaSR and NF- $\kappa \mathrm{B}$ signalling pathway in IPEC-J2 cells are shown in Figs. 3 and 4. In comparison with the control cells, R568 and TPT treatments significantly up-regulated CaSR level, whereas NPS-2143 reduced CaSR protein level $(P<0.05)$. R568 decreased the protein level of $\mathrm{p}-\mathrm{NF}-\kappa \mathrm{B}$ and $\mathrm{I} \kappa \mathrm{B}(P<0.05)$. TPT decreased the protein level of $\mathrm{I} \kappa \mathrm{B}$, whereas NPS-2143 significantly increased the levels of $\mathrm{p}-\mathrm{NF}-\kappa \mathrm{B}, \mathrm{IKK} \alpha / \beta$ and $\mathrm{I} \kappa \mathrm{B}(P<0 \cdot 05)$. NPS-2143 with TPT treatment up-regulated $\mathrm{p}-\mathrm{NF}-\kappa \mathrm{B}(P<0.05)$.

\section{Discussion}

CaSR plays a key role in modulating fluid secretion and absorption in the GI tract ${ }^{(23)}$. Recent studies have demonstrated that CaSR may serve as novel therapeutic targets for the treatment of inflammatory bowel diseases ${ }^{(21,24,25)}$. In this study, activation of CaSR through its ligands, aromatic amino acids, demonstrated anti-inflammatory effect in response to LPS challenge, which is mediated through the inhibition of the NF$\kappa \mathrm{B}$ signalling pathway.

LPS has been widely used for induction of inflammatory response in numerous animal and in vitro models ${ }^{(26)}$. Intraperitoneal LPS injection can trigger the systemic inflammation mirrored by increased circulation of pro-inflammatory cytokines through the activation of the NF- $\kappa \mathrm{B}$ signalling pathway $^{(27)}$. It has been shown that intraperitoneal LPS injection aggravates the inflammatory response of the intestinal mucosa and causes tissue damage to the intestinal epithelium and the intestinal barrier functions in piglets $^{(28)}$. In this study, intraperitoneal injection of LPS led to systemic and intestinal inflammation, increased the MPO activity in the proximal and distal colon and increased the serum concentrations of IL- $1 \beta$, IL-6, IL-8, IL-12, GM-CSF and TNF- $\alpha$.

However, dietary supplementation of aromatic amino acids alleviated intestinal inflammation. First, aromatic amino acids significantly improved histopathological grading of ileum and colon and MPO activity in the posterior colon in the LPSchallenged piglets. MPO was released into the extracellular space after phagocyte activation to induce damage to the host tissue at inflammatory sites. The increased intestinal MPO levels as a biomarker of oxidative stress were found in inflammatory bowel disease ${ }^{(29)}$.

Consistent with the result of MPO, supplementation of aromatic amino acids down-regulated the mRNA levels of proinflammatory cytokines in intestine tissue of LPS-treated piglets. During intestinal inflammation, mucosal immune dysfunction and innate immune cell activation result in the excess production of pro-inflammatory cytokines ${ }^{(30)}$. Elevated expression of pro-inflammatory cytokines is closely related to increased intestinal permeability ${ }^{(31)}$. Conversely, aromatic amino acids increased the levels of anti-inflammatory cytokines, such as IL-4 and TGF- $\beta$, which contribute to the repair of the intestinal epithelium. Collectively, feed supplementation of aromatic amino acids decreased mRNA levels of certain pro-inflammatory cytokines in the jejunum, ileum and colon and enhanced mRNA levels of anti-inflammatory cytokines.

The NF- $\kappa$ B pathway plays a pivotal role in the modulation of the inflammatory response and cytokine gene expression. The activation of $\mathrm{NF}-\kappa \mathrm{B}$ signalling can induce the mucosal immune 
Table 6. Effects of dietary supplementation with tryptophan, phenylalanine and tyrosine (TPT) on the relative protein levels of calcium-sensing receptor (CaSR) and NF-kB signalling pathway in the jejunum ileum and anterior colon of piglets

(Mean values with their standard errors, $n 8$ per treatment)

\begin{tabular}{|c|c|c|c|c|c|c|c|c|c|c|c|}
\hline \multirow[b]{3}{*}{ Items } & \multicolumn{4}{|c|}{ Control diet } & \multicolumn{4}{|c|}{ TPT diet } & & & \\
\hline & \multicolumn{2}{|c|}{ Saline } & \multicolumn{2}{|c|}{ LPS } & \multicolumn{2}{|c|}{ Saline } & \multicolumn{2}{|c|}{ LPS } & \multicolumn{3}{|c|}{$P$} \\
\hline & Mean & SEM & Mean & SEM & Mean & SEM & Mean & SEM & Diet & LPS & Diet $\times$ LPS \\
\hline \multicolumn{12}{|l|}{ Jejunum } \\
\hline CaSR & $1.00^{\mathrm{b}}$ & 0.08 & $1.29^{b}$ & 0.07 & $1.74^{\mathrm{a}}$ & $0 \cdot 10$ & $1.23^{\mathrm{b}}$ & 0.18 & 0.047 & 0.446 & 0.025 \\
\hline PLC $\beta 2$ & $1.00^{\mathrm{b}}$ & 0.06 & $1.09^{b}$ & 0.02 & $1.36^{\mathrm{a}}$ & 0.01 & $1.34^{\mathrm{a}}$ & 0.03 & $<0.001$ & 0.413 & 0.146 \\
\hline $\mathrm{IKKa} / \beta$ & $1.00^{\mathrm{a}}$ & 0.01 & $1 \cdot 11^{\mathrm{a}}$ & 0.02 & $0.80^{a, b}$ & 0.05 & $0.76^{\mathrm{b}}$ & 0.02 & $<0.001$ & 0.283 & 0.026 \\
\hline$N F-k B$ & $1.00^{\mathrm{b}}$ & 0.05 & $1.42^{\mathrm{a}}$ & 0.05 & $0.81^{\mathrm{b}}$ & 0.01 & $0.97^{\mathrm{b}}$ & 0.05 & $<0.001$ & $<0.001$ & 0.018 \\
\hline p-NF-kB & $1.00^{\mathrm{a}, \mathrm{b}}$ & 0.02 & $1 \cdot 17^{\mathrm{a}}$ & 0.04 & $1.03^{\mathrm{a}, \mathrm{b}}$ & 0.10 & $0.79^{\mathrm{b}}$ & 0.10 & 0.072 & 0.656 & 0.042 \\
\hline I $\mathrm{B}$ & $1.00^{\mathrm{a}, \mathrm{b}}$ & 0.04 & $1 \cdot 17^{\mathrm{a}}$ & 0.02 & $0.71^{a, b}$ & 0.06 & $0.66^{\mathrm{b}}$ & 0.03 & $<0.001$ & 0.211 & 0.039 \\
\hline \multicolumn{12}{|l|}{ Ileum } \\
\hline CaSR & $1.00^{\mathrm{C}}$ & 0.03 & $1.23^{\mathrm{b}}$ & 0.02 & $1 \cdot 22^{b}$ & 0.00 & $1.53^{\mathrm{a}}$ & 0.09 & 0.001 & 0.001 & 0.484 \\
\hline PLC $\beta 2$ & $1.00^{\mathrm{b}}$ & 0.14 & $1 \cdot 12^{\mathrm{b}}$ & 0.01 & $1.43^{\mathrm{a}}$ & 0.05 & $1.54^{\mathrm{a}}$ & 0.00 & 0.002 & 0.178 & 0.951 \\
\hline $\mid \mathrm{KK} a / \beta$ & $1.00^{\mathrm{b}}$ & 0.02 & $1.00^{\mathrm{b}}$ & 0.01 & $1 \cdot 14^{\mathrm{a}}$ & 0.03 & $1 \cdot 18^{\mathrm{a}}$ & 0.03 & $<0.001$ & 0.394 & 0.444 \\
\hline NF-kB & 1.00 & 0.01 & 0.95 & 0.04 & 1.03 & 0.03 & 1.07 & 0.03 & 0.130 & 0.959 & 0.118 \\
\hline p-NF-kB & $1.00^{\mathrm{b}}$ & 0.15 & $1 \cdot 29^{a, b}$ & 0.03 & $1.36^{\mathrm{a}}$ & 0.09 & $1.22^{a, b}$ & 0.05 & 0.135 & 0.397 & 0.042 \\
\hline $\mathrm{I}_{k \mathrm{~B}}$ & $1.00^{\mathrm{b}}$ & 0.01 & $1.41^{\mathrm{a}}$ & 0.05 & $0.94^{b}$ & 0.03 & $0.79^{c}$ & 0.05 & $<0.001$ & 0.013 & $<0.001$ \\
\hline \multicolumn{12}{|c|}{ Anterior colon } \\
\hline CaSR & $1.00^{\mathrm{b}}$ & 0.01 & $1 \cdot 25^{\mathrm{a}}$ & 0.01 & $1 \cdot 14^{\mathrm{a}, \mathrm{b}}$ & 0.03 & $0.95^{\mathrm{b}}$ & 0.06 & 0.014 & 0.251 & $<0.001$ \\
\hline PLC $\beta 2$ & $1.00^{\mathrm{b}}$ & 0.05 & $1 \cdot 34^{\mathrm{a}}$ & 0.11 & $1 \cdot 20^{\mathrm{a}}$ & 0.07 & $1.05^{\mathrm{b}}$ & 0.06 & 0.497 & 0.200 & 0.008 \\
\hline IKKa/ $\beta$ & $1.00^{\mathrm{b}}$ & 0.10 & $1 \cdot 24^{\mathrm{a}}$ & 0.06 & $1 \cdot 23^{\mathrm{a}}$ & 0.04 & $0.98^{\mathrm{b}}$ & 0.12 & 0.919 & 0.938 & 0.021 \\
\hline$N F-k B$ & $1.00^{\mathrm{a}}$ & 0.01 & $0.80^{\mathrm{b}}$ & 0.03 & $1.04^{\mathrm{a}}$ & 0.07 & $1.02^{\mathrm{a}}$ & 0.05 & 0.034 & 0.061 & 0.129 \\
\hline p-NF-kB & $1.00^{\mathrm{a}}$ & 0.06 & $1 \cdot 10^{\mathrm{a}}$ & 0.04 & $0.91^{\mathrm{a}, \mathrm{b}}$ & 0.05 & $0.72^{\mathrm{b}}$ & 0.09 & 0.012 & 0.489 & 0.064 \\
\hline$I_{k} B$ & $1.00^{\mathrm{b}}$ & 0.04 & $1 \cdot 22^{\mathrm{a}, \mathrm{b}}$ & 0.08 & $1.47^{\mathrm{a}}$ & 0.02 & $1.11^{\mathrm{b}}$ & 0.08 & 0.015 & 0.277 & 0.001 \\
\hline
\end{tabular}

Control, basal diet; TPT, basal diet supplemented with $0.16 \%$ tryptophan $+0.41 \%$ phenylalanine $+0.22 \%$ tyrosine; LPS, lipopolysaccharide; PLC $\beta$, phospholipase C $\beta$; IKKa/ $\beta$, inhibitor of NF-kB kinase $\alpha / \beta$; p-NF- $k B$, phosphorylated NF- $k B$; $\mathrm{I} \mathrm{KB}$, inhibitor of $\mathrm{NF}-\mathrm{KB}$.

a,b,c Mean values within a row with unlike superscript letters were significantly different $(P<0.05)$. 


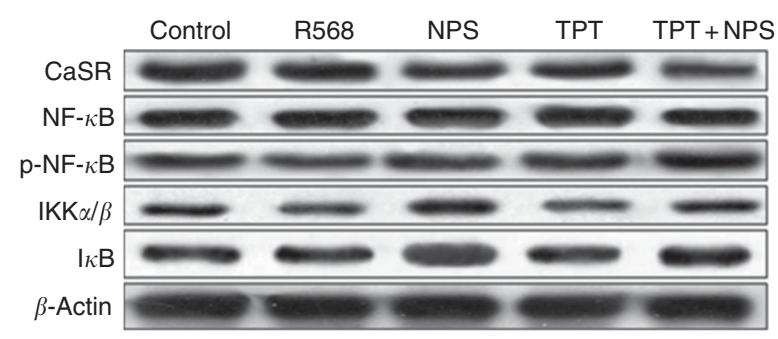

Fig. 3. Representive Western blot images of IPEC-J2 supplemented with tryptophan, phenylalanine and tyrosine (TPT) and calcium-sensing receptor (CaSR) agitation or inhibition. p-NF-kB, phosphorylated NF-kB; IKK, inhibitor of $\mathrm{NF}-\kappa \mathrm{B}$ kinase; $\mathrm{I}_{\kappa} \mathrm{B}$, inhibitor of NF-kB .

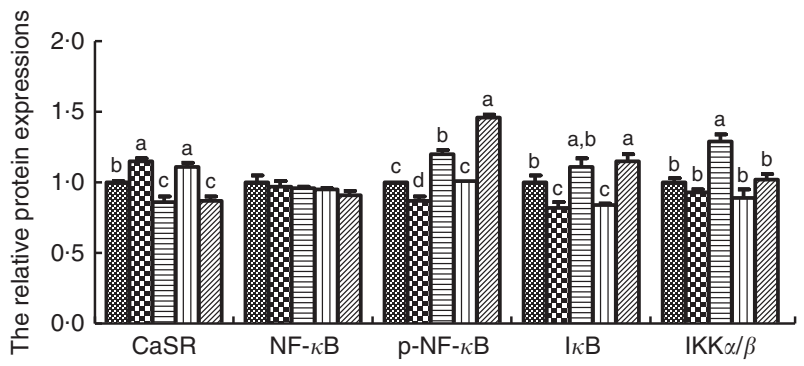

Fig. 4. Effects of tryptophan, phenylalanine and tyrosine (TPT) supplementation and calcium-sensing receptor (CaSR) agitation or inhibition on the protein levels of NF-KB signalling pathway in lipopolysaccharide (LPS)challenged IPEC-J2. Values are means ( $n 4$ independent experiments), with their standard errors represented by vertical bars. ${ }^{a, b, c, d}$ Mean values with unlike letters were significantly different $(P<0.05)$. 圈, Control; $:$, R568; 目, NPS; 皿, TPT; 四, TPT + NPS. p-NF-kB, phosphorylated NF-kB; IkB, inhibitor of $\mathrm{NF}-\mathrm{kB}$; IKK, inhibitor of NF-kB kinase.

response and early pathologic reactions of inflammation in segments of the intestine ${ }^{(32)}$. This study demonstrates that additional aromatic amino acids in the diet could reduce the LPS-induced activation of the NF- $\kappa \mathrm{B}$ signalling pathway and decrease the level of IKK $\alpha / \beta$, p-NF- $\kappa \mathrm{B}$ and I $\kappa \mathrm{B}$ from the jejunum to the anterior colon. The observed inhibitory effect was shown to be associated with the activation of the CaSR signalling pathway by aromatic amino acids ${ }^{(33)}$. In this study, dietary supplementation with aromatic amino acids increased the protein levels of PLC $\beta 2$ in the intestine from the jejunum to the anterior colon, whereas the protein levels of CaSR were elevated in the jejunum and ileum but not in the anterior colon. In the taste signalling pathway, activation of PLC $\beta 2$ results in a transient increase in intracellular $\mathrm{Ca}$ ions ${ }^{(34)}$. Then, transient receptor potential melastatin channel subtype 5 (TRPM5) is activated by the changing intracellular $\mathrm{Ca}$ levels, causing depolarisation of taste receptor cells ${ }^{(35)}$. Interestingly, the colocalisation of PLC $\beta 2$ with TRPM 5 in colon sections was not observed as in the other regions of the gut ${ }^{(36)}$. Thus, the diversity of PLC $\beta 2$ level affected by aromatic amino acids may stem from the limit of upstream and downstream signalling molecules in different segments of the intestine. L-Amino acids are allosteric activators of CaSR with the following order of affinity: aromatic amino acids $>$ aliphatic amino acids $>$ polar amino acids ${ }^{(37,38)}$. Recent studies have shown that the aromatic amino acid L-Trp in intestinal cells can recruit $\beta$-arrestin2 through the activation of the CaSR signalling pathway, which inhibits the NF- $\kappa \mathrm{B}$ signalling pathway, blocks inflammatory 
(a)

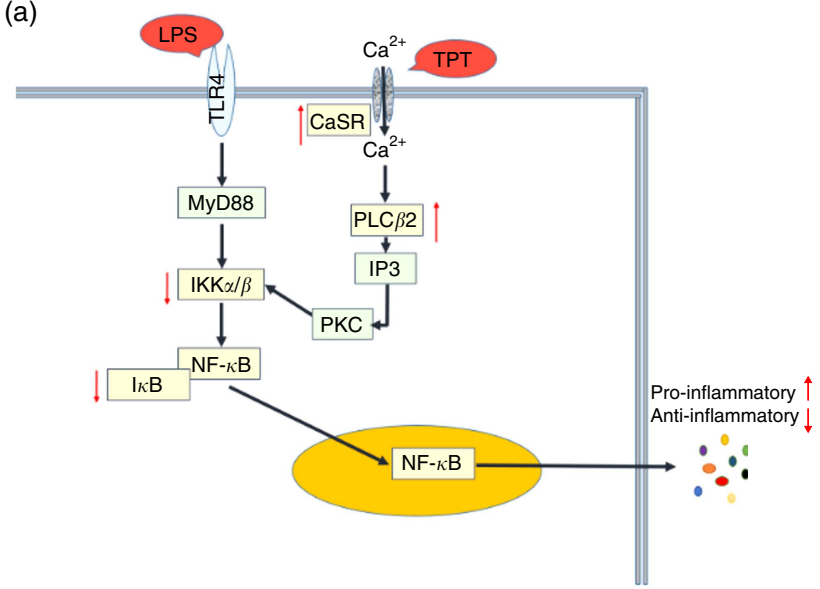

(b)

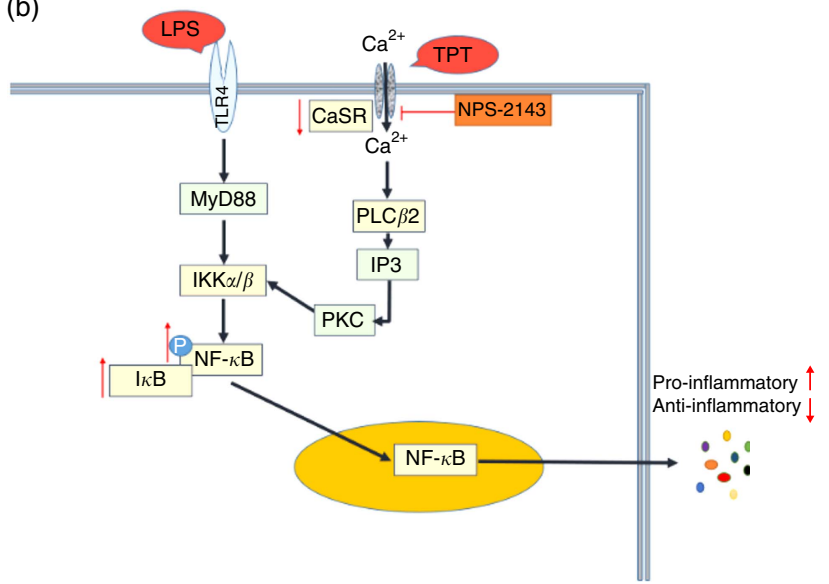

Fig. 5. Cross talk of toll-like receptor 4 (TLR4) and calcium-sensing receptor (CaSR) pathways. (a) Tryptophan, phenylalanine and tyrosine (TPT) supplementation in pig diet increased the mRNA level of CaSR and reduced the activity of the NF-kB pathway induced by lipopolysaccharide (LPS) challenge, leading to the inhibition of cytokine production; (b) in LPS challenged IPEC-J2 cells, CaSR inhibitor (NPS-2143) suppressed the activity of CaSR, resulting in the phosphorylation of NF- $\mathrm{KB}$ and the recovery of cytokine secretion in inflammation. Myeloid differentiation factor 88 (MyD88) is a key adaptor in the TLR signalling pathway. It mediates the activation of downstream NF- $\mathrm{kB}$. Inositol 1,4,5-triphosphate (IP3) is a messenger to activate protein kinase $\mathrm{C}(\mathrm{PKC})$ and induce the cellular cascade response.

signal transduction and consequently exerts anti-inflammatory $\operatorname{activity}^{(39,40)}$.

As a nutrient-sensing receptor, CaSR plays an important role in the maintenance of immune homoeostasis in intestinal mucosa ${ }^{(25,41)}$. Recent studies have proven that CaSR is an important target for the prevention of chronic inflammation and tumour progression ${ }^{(39,42,43)}$. To further explore the role of the CaSR signalling pathway in the regulation of aromatic amino acids on the intestinal inflammatory response, the in vitro study was performed in the intestinal epithelial cell line. In IPEC-J2 cells, the mRNA levels of pro-inflammatory cytokines, such as IL- $1 \beta$ and IL-6, were significantly reduced by the addition of aromatic amino acids. The treatment of IPEC-J2 cells with R568, a CaSR specific activator ${ }^{(44)}$, also yielded similar results with TPT supplementation in this study. NPS-2143 can bind to specific amino acid binding sites on seven-transmembrane $\alpha$-helices to inhibit the effect of CaSR activators on the CaSR signalling pathway ${ }^{(45,46)}$. As expected, the addition of the CaSR antagonist, NPS-2143, significantly reduced the protein levels of CaSR, $\mathrm{p}-\mathrm{NF}-\kappa \mathrm{B}$ and $\mathrm{I} \kappa \mathrm{B}$. Intriguingly, it also blocked the anti-inflammatory effects of aromatic amino acids, which further indicated involvement of the CaSR signalling pathway.

This study shows that dietary supplementation with aromatic amino acids could regulate the secretion of inflammatory cytokines induced by LPS in the intestine of piglets. The antiinflammatory effect might be mediated via the activation of CaSR, which subsequently inhibits NF- $\kappa$ B signalling pathways. Our study highlighted dietary supplementation of aromatic amino acids as a nutritional strategy to alleviate intestinal stress in a pig model. CaSR signalling may be a potential target to reduce enteric inflammation in the livestock industry. LPS-induced cell injury is predominantly mediated by the activation of TLR $4^{(47)}$. The upregulated mRNA expression of CaSR and decreasing level of $\mathrm{IKK} \alpha / \beta$-I $\kappa \mathrm{B}$ in the LPS-reduced pigs followed the supplementation of TPT. In the in vivo study, the inhibitor of CaSR activated I $\kappa \mathrm{B}$ expression, leading to appreciable cytokine production. Together, the regulatory effects of TPT on inflammation followed the cross talk between CaSR and TLR 4 pathway (Fig. 5). Given that excessive activation of either $\mathrm{I} \kappa \mathrm{B}$ or NF- $\kappa \mathrm{B}$ has been associated with inflammatory tissue injury, the new insight on dietary aromatic amino acid supplementation may have therapeutic implications.

\section{Acknowledgements}

This study was supported by the National Key R\&D Program (2017YFD0500503), Key Programs of Frontier Scientific Research of the Chinese Academy of Sciences (QYZDY-SSWSMC008), National Natural Science Foundation of China (nos 31330075, 31672433, 31501964 and 31560640), the Earmarked Fund for China Agriculture Research System (CARS-35) and Youth Innovation Team Project of ISA, CAS (2017QNCXTD_TBE).

B. T. and Y. Y. designed the research and analysed the data. H. L., B. H., J. L., J. W. and G. G. conducted the research. H. L., B. T., P. L. and P. J. wrote the article. B. T. and Y. Y. had primary responsibility for the final content, and all authors read and approved the final manuscript.

The authors declare that there are no conflicts of interest.

\section{Supplementary material}

For supplementary material/s referred to in this article, please visit https://doi.org/10.1017/S0007114518002891

\section{References}

1. Tan B, Li XG, Kong X, et al. (2009) Dietary L-arginine supplementation enhances the immune status in early-weaned piglets. Amino acids 37, 323-331.

2. Ren W, Yin J, Chen S, et al. (2016) Proteome analysis for the global proteins in the jejunum tissues of enterotoxigenic Escherichia coli-infected piglets. Sci Rep 6, 25640. 
3. Xiao D, Wang Y, Liu G, et al. (2014) Effects of chitosan on intestinal inflammation in weaned pigs challenged by enterotoxigenic Escherichia coli. PLOS ONE 9, e104192.

4. Xiao D, Tang Z, Yin Y, et al. (2013) Effects of dietary administering chitosan on growth performance, jejunal morphology, jejunal mucosal sIgA, occluding, claudin-1 and TLR4 expression in weaned piglets challenged by enterotoxigenic Escherichia coli. Int Immunopharmacol 17, 670-676.

5. Harada K, Ohira S, Isse K, et al. (2003) Lipopolysaccharide activates nuclear factor-kappaB through Toll-like receptors and related molecules in cultured biliary epithelial cells. Lab Invest 83, 1657-1667.

6. Maeda S \& Omata M (2008) Inflammation and cancer: role of nuclear factor-kappaB activation. Cancer Sci 99, 836-842.

7. Beutler B (2000) Tlr4: central component of the sole mammalian LPS sensor. Curr Opin Immunol 12, 20-26.

8. Liu Y, Huang J, Hou Y, et al. (2008) Dietary arginine supplementation alleviates intestinal mucosal disruption induced by Escherichia coli lipopolysaccharide in weaned pigs. $\mathrm{Br} \mathrm{J}$ Nutr 100, 552-560.

9. Tak PP \& Firestein GS (2001) NF- $\kappa$ B: a key role in inflammatory diseases. J Clin Invest 107, 7.

10. Schottelius A \& Baldwin A Jr (1999) A role for transcription factor NF- $\kappa \mathrm{B}$ in intestinal inflammation. Int J Colorectal Dis 14, $18-28$.

11. Rossol M, Pierer M, Raulien N, et al. (2012) Extracellular $\mathrm{Ca}^{2+}$ is a danger signal activating the NLRP3 inflammasome through $\mathrm{G}$ protein-coupled calcium sensing receptors. Nat Commun 3, 1329.

12. Wu C-L, Wu Q-Y, Du J-J, et al. (2015) Calcium-sensing receptor in the $\mathrm{T}$ lymphocyte enhanced the apoptosis and cytokine secretion in sepsis. Mol Immunol 63, 337-342.

13. Busque SM, Kerstetter JE, Geibel JP, et al. (2005) L-Type amino acids stimulate gastric acid secretion by activation of the calcium-sensing receptor in parietal cells. Am J Physiol Gastrointest Liver Physiol. 289, G664-G669.

14. Conigrave AD, Mun H-C \& Lok H-C (2007) Aromatic L-amino acids activate the calcium-sensing receptor. J Nutr 137, 1524S-1527S

15. Mine Y \& Zhang H (2015) Calcium-sensing receptor (CaSR)mediated anti-inflammatory effects of $\mathrm{L}$-amino acids in intestinal epithelial cells. J Agric Food Chem 63, 9987-9995.

16. National Research Council (2013) Nutrient Requirements of Swine. Washington, DC: National Academies Press.

17. Yuan D, Hussain T, Tan B, et al. (2017) The evaluation of antioxidant and anti-inflammatory effects of Eucommia ulmoides flavones using diquat-challenged piglet models. Oxid Med Cell Longev 2017, 1-9.

18. Huang B, Xiao D, Tan B, et al. (2015) Chitosan oligosaccharide reduces intestinal inflammation that involves calcium-sensing receptor (CaSR) activation in lipopolysaccharide (LPS)-challenged piglets. J Agric Food Chem 64, 245-252.

19. Barreau F, Ferrier L, Fioramonti J, et al. (2004) Neonatal maternal deprivation triggers long term alterations in colonic epithelial barrier and mucosal immunity in rats. Gut 53, 501-506.

20. Maslowski KM, Vieira AT, Ng A, et al. (2009) Regulation of inflammatory responses by gut microbiota and chemoattractant receptor GPR43. Nature 461, 1282.

21. Huang B, Xiao D, Tan B, et al. (2016) Chitosan oligosaccharide reduces intestinal inflammation that involves calcium-sensing receptor (CaSR) activation in lipopolysaccharide (LPS)-challenged piglets. J Agric Food Chem 64, 245-252.

22. Tan B, Yin Y, Kong X, et al. (2010) L-Arginine stimulates proliferation and prevents endotoxin-induced death of intestinal cells. Amino Acids 38, 1227-1235.
23. Geibel JP \& Hebert SC (2009) The functions and roles of the extracellular $\mathrm{Ca}^{2+}$-sensing receptor along the gastrointestinal tract. Annu Rev Physiol 71, 205-217.

24. Tang L, Cheng CY, Sun X, et al. (2016) The extracellular calcium-sensing receptor in the intestine: evidence for regulation of colonic absorption, secretion, motility, and immunity. Front Physiol 7.

25. Cheng SX, Lightfoot YL, Yang T, et al. (2014) Epithelial CaSR deficiency alters intestinal integrity and promotes proinflammatory immune responses. FEBS Lett $\mathbf{5 8 8}$, 4158-4166.

26. Walton KL, Collins L \& Sartor RB (2006) Lipopolysaccharide activates innate immune responses in murine intestinal myofibroblasts. FASEB J 20, A1465.

27. Blackwell TS, Yull FE, Chen C-L, et al. (2000) Multiorgan nuclear factor kappa $\mathrm{B}$ activation in a transgenic mouse model of systemic inflammation. Am J Respir Crit Care Med 162, 1095-1101.

28. Strober W, Fuss I \& Mannon P (2007) The fundamental basis of inflammatory bowel disease. J Clin Invest 117, 514 .

29. Algieri F, Zorrilla P, Rodriguez-Nogales A, et al. (2013) Intestinal anti-inflammatory activity of hydroalcoholic extracts of Phlomis purpurea L. and Phlomis lychnitis L. in the trinitrobenzenesulphonic acid model of rat colitis. J Ethnopharmacol 146, 750-759.

30. Wallach D, Varfolomeev E, Malinin N, et al. (1999) Tumor necrosis factor receptor and Fas signaling mechanisms. Annu Rev Immunol 17, 331-367.

31. Förster C (2008) Tight junctions and the modulation of barrier function in disease. Histochem Cell Biol 130, 55-70.

32. Atreya I, Atreya R \& Neurath M (2008) NF- $\kappa$ B in inflammatory bowel disease. J Intern Med 263, 591-596.

33. Yousef M, Pichyangkura R, Soodvilai S, et al. (2012) Chitosan oligosaccharide as potential therapy of inflammatory bowel disease: therapeutic efficacy and possible mechanisms of action. Pharmacol Res 66, 66-79.

34. Clapp TR, Stone LM, Margolskee RF, et al. (2001) Immunocytochemical evidence for co-expression of type III IP3 receptor with signaling components of bitter taste transduction. BMC Neurosci $\mathbf{2}, 6$.

35. Behrens M \& Meyerhof W (2010) Oral and extraoral bitter taste receptors. In Sensory and Metabolic Control of Energy Balance, pp. 87-99 [W Meyerhof, U Beisiegel and H-G Joost, editors]. Berlin, Heidelberg: Springer Berlin Heidelberg.

36. Bezencon C, le Coutre J \& Damak S (2007) Taste-signaling proteins are coexpressed in solitary intestinal epithelial cells. Chem Senses 32, 41-49.

37. Conigrave AD \& Brown EM (2006) Taste receptors in the gastrointestinal tract. II. L-Amino acid sensing by calciumsensing receptors: implications for GI physiology. Am J Physiol Gastrointest Liver Physiol 291, G753-G761.

38. Conigrave AD, Franks AH, Brown EM, et al. (2002) L-Amino acid sensing by the calcium-sensing receptor: a general mechanism for coupling protein and calcium metabolism? Eur J Clin Nutr 56, 1072-1080.

39. Zhang H, Kovacs-Nolan J, Kodera T, et al. (2015) Gammaglutamyl cysteine and gamma-glutamyl valine inhibit TNFalpha signaling in intestinal epithelial cells and reduce inflammation in a mouse model of colitis via allosteric activation of the calcium-sensing receptor. Biochim Biophys Acta 1852, 792-804.

40. Mine Y \& Zhang H (2015) Calcium-sensing receptor (CaSR)-mediated anti-inflammatory effects of L-amino acids in intestinal epithelial cells. J Agric Food Chem $\mathbf{6 3}$, 9987-9995. 
41. Macleod RJ (2013) CaSR function in the intestine: hormone secretion, electrolyte absorption and secretion, paracrine non-canonical Wnt signaling and colonic crypt cell proliferation. Best Pract Res Clin Endocrinol Metab 27, 385-402.

42. Cheng SX, Lightfoot YL, Yang T, et al. (2014) Epithelial CaSR deficiency alters intestinal integrity and promotes proinflammatory immune responses. FEBS Lett 588, 4158-4166.

43. MacLeod RJ (2013) Extracellular calcium-sensing receptor/ PTH knockout mice colons have increased Wnt/ $\beta$-catenin signaling, reduced non-canonical Wnt signaling, and increased susceptibility to azoxymethane-induced aberrant crypt foci. Lab Invest $\mathbf{9 3}, 520-527$.
44. Davey AE, Leach K, Valant C, et al. (2012) Positive and negative allosteric modulators promote biased signaling at the calcium-sensing receptor. Endocrinology 153, 1232-1241.

45. Nemeth EF, Delmar EG, Heaton WL, et al. (2001) Calcilytic compounds: potent and selective $\mathrm{Ca}^{2+}$ receptor antagonists that stimulate secretion of parathyroid hormone. J Pharmacol Exp Ther 299, 323-331.

46. Soudijn W, Van Wijngaarden I \& IJzerman AP (2004) Allosteric modulation of $\mathrm{G}$ protein-coupled receptors: perspectives and recent developments. Drug Discov Today 9, 752-758.

47. Elner SG, Petty HR, Elner VM, et al. (2005) TLR4 mediates human retinal pigment epithelial endotoxin binding and cytokine expression. Invest Ophthalmol Vis Sci 46, 4627-4633. 